No organic compounds of this type have been proposed previously as alkalimetric standards. Potassium bi-iodate, already in use for alkalimetry and iodimetry ${ }^{6}$, is a similar acid salt of an inorganic monobasic acid. Alkali metal hydrogen salts of organic dibasic acids already used as standards suffer from several disadvantages not possessed by the substance now advocated. For example, potassium hydrogen phthalate must be recrystallized from water above $35^{\circ} 7$; potassium tetroxalate must be kept under conditions of definite vapour pressure ${ }^{8}$; potassium hydrogen oxalate cannot be recrystallized from water without change ${ }^{9}$; potassium hydrogen tartrate has a low solubility in water and is difficult to obtain pure ${ }^{10}$.

This investigation is being continued, and will be discussed in greater detail elsewhere.

Chemistry Department,

City College of Technology,

Liverpool 2. March 22.

${ }^{1}$ Ross, J. D. M., and Morrison, 'T. J., J. Chem. Soc., 1016 (1933). ${ }^{2}$ Speakman, J. C., and Smith, N., Nature, 155, 698 (1945).

${ }^{3}$ Smith, N., and Speakman, J. C., Trans. Farad. Soc., 44, 1031 (1948). "Heilbron, I. M., "Dictionary of Organic Compounds" (Eyre and Spottiswoode, London, 2nd edit., 1942).
Solilon, I. M., "ictionary or Organic

${ }^{5} \mathrm{Knox}$, J., and Richards, M. B., J. Chem. Soc., 115. 515 (1919).

Than, C. von, Math. naturw. Ber. Ungarn, 7, 295 (1877). Kolthoff, I. M., and van Berk, L. H., J. Amer. Chem. Soc., 48, 2799 (1926). ' Smith, S. B., J. Amer. Chem. Soc., 53, 3711 (1931).

${ }^{8}$ Schmidt, K. O., Z. anal. Chem., 71, 277 (1927).

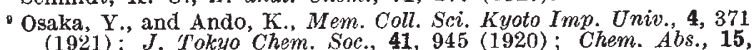
(1921); J. 'Tokyo Chem. Soc.,

${ }^{10}$ Bornträger, H., Chom. Z., 5, 519 (1881); 14, 1206 (1890); Z. anat. Chem., 25, 333 (1886); 31, 43 (1892); 33, 713 (1894). Favrel, (x., Ann. chim. anal. chim. app., 9, 161 (1927).

\section{Thermal Transformations of the Aluminas and their Hydrates}

SEVERAL polymorphic forms of anhydrous alumina derived from the calcination of hydrated aluminas have been described by various authors ${ }^{1-3}$. The interpretations made of the relationships which exist between the hydrated and anhydrous forms presuppose that the dehydration of gibbsite and bayerite occur through böhmite, and that the dehydration of the bohmite derived from gibbsite can unaccountably yield one of two series of transformations before $\alpha$ alumina is finally produced.

Work which we have carried out over a number of years and which will be published elsewhere has led us to believe that the böhmite which is encountered in the dehydration of both gibbsite and bayerite is produced by secondary reactions between the original dehydration products, which are virtually anhydrous aluminas, and the water which is released during the reaction, and our conclusions are illustrated in the accompanying diagram.

Bayerite gives rise on calcination to $\gamma$-alumina which is capable only of hydration to böhmite. Böhmite also yields only $\gamma$-alumina, so both these hydrates give rise to the $\gamma-\delta-\theta^{2}$ forms of anhydrous alumina.

Gibbsite, on the other hand, yields initially another form of alumina. This anhydrous alumina has a crystal form for which the lattice spacings of the two most intense lines have $d$ values $2 \cdot 11$ and $1 \cdot 39$, the latter being identical with that of one of the major lines of $\gamma$-alumina. It is convenient to label this $\chi$-alumina, and we have found that this is, in fact, only one of the components of the $(\gamma+\chi)$

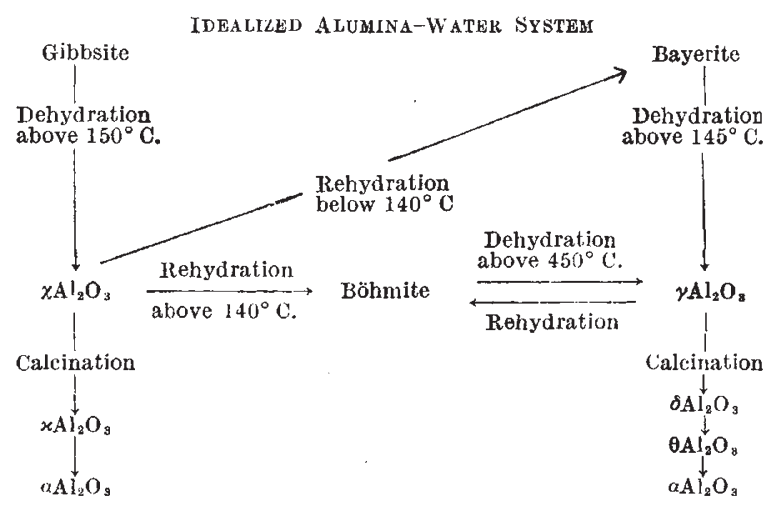

mixture derived from gibbsite which had previously been designated $\chi^{3}$. True $\chi$-alumina is capable of hydration to bayerite at temperatures below $140^{\circ}$, and above $140^{\circ}$ to böhmite, and on further calcination yields true $x$-alumina before final conversion to $\alpha$. In practice, therefore, we find on dehydrating gibbsite a mixture of $\chi$-alumina and böhmite, the latter being derived from the secondary reaction of $\chi$ with water. Subsequent calcination at higher temperatures therefore gives rise to mixtures of the two series of anhydrous forms, that is, $\gamma-\delta-\theta-\alpha$, associated with the böhmite component, and $\chi-x-\alpha$ associated with the original dehydration product $\chi$.

We are indebted to Mr. H. P. Rooksby of the Research Laboratories of the General Electric Conpany for his interest and helpful discussion.

Margaret K. B. DAY

VERNON J. HILL

Research Laboratories,

The British Aluminium Co., Ltd.,

Chalfont Park, Gerrards Cross, Bucks. Feb. 28. ${ }^{1}$ Weiser, H. B., and Milligan, W. O., J. Phys. Chem., 38, 3010 (1932); and Eng. Chem., Indust. Edit., 37, 158 (1945).

${ }^{2}$ Rooksby, H. P., "X-Ray Identiflcations and Crystal Structures of Clay Minerals", 244 (Mineralogical Society, 1951).

${ }^{3}$ Stumpf, H. C., Russell, A. S., et al., Indust. and Eng. Chem., 42, $7,1398(1950)$.

\section{Chromatography of Rubber Accelerators and Anti-Oxidants on Silica Gel}

ThE chromatographic separation on alumina columns of certain constituents from the acetone extracts of vulcanized rubbers has been reported by Bellamy and co-workers ${ }^{1}$ and by Mann ${ }^{2}$. As an adsorbent for such materials, alumina suffers from certain disadvantages, in particular, its tendency to favour chemical change in labile adsorbates. 'The successful use of silica gel/'Celite' for the chromatographic separation of a variety of ingredients from propellants and high explosives $s^{3,4}$ suggested that this adsorbent might prove equally useful for the separation of the ingredients of vulcanized rubbers, and this has, in fact, been borne out by recent work in this laboratory. 'The procedure adopted for the qualitative examination of a rubber extract is as follows. A number of separate portions of the extract (each equivalent to $0 \cdot 2-0 \cdot 4 \mathrm{gm}$. of the rubber) are chromatographed on 1-cm. diameter columns using a series of different binary solvent mixtures as developers. When the extruded columns have been streaked with appropriate reagents, the positions of the zones, together with the colours of the streaks, give a reason- 